\title{
Long-Term Safety and Effectiveness of Thyrotropin Alfa in Japanese Patients: A Post-Marketing Surveillance Study
}

\author{
Rie Kanamori · Shiho Yamane · Takeshi Seto
}

Received: May 6, 2021 / Accepted: July 16, 2021 / Published online: August 13, 2021

(C) The Author(s) 2021

\section{ABSTRACT}

Introduction: Real-world evidence of the safety and effectiveness of recombinant human thyroid-stimulating hormone (rhTSH; thyrotropin alfa) in Japanese patients is lacking.

Methods: This was a post-marketing surveillance study that included all Japanese patients who received thyrotropin alfa, either as a supporting diagnostic from January 2009 to December 2016, or as adjunctive treatment for ablation from May 2012 to October 2018. Information was collected on patient demographics, thyroid cancer characteristics, adverse drug reactions (ADRs), scintigraphy, serum thyroglobulin (Tg) testing, and hypothyroidism symptoms.

Results: A total of 9268 patients were included in the safety analysis and 9031 in the effectiveness analysis. In the safety analysis set, 3444 patients received thyrotropin alfa as a diagnostic and 5822 received it as treatment. ADRs occurred in $7.1 \%(n=660)$ of patients, including $9.4 \%(n=324)$ of patients who received

R. Kanamori $(\bowtie)$

Sanofi Genzyme Medical, Oncology Medical, Sanofi

K.K., Tokyo Opera City Tower, 3-20-2 Nishi

Shinjuku, Shinjuku-ku, Tokyo 163-1488, Japan

e-mail: rie2.kanamori@sanofi.com

S. Yamane $\cdot$ T. Seto

Medical Affairs, Post-Authorization Regulatory

Studies, Sanofi K.K., Tokyo, Japan thyrotropin alfa as a diagnostic and 5.8\% $(n=336)$ of patients who received it as treatment. Nausea was the most common ADR (4.0\% of overall safety population). Among patients who received thyrotropin alfa as a diagnostic $(n=1835)$, the Tg test was positive in $53.6 \%$ after the second dose. The scintigram was rated as "readable" in 3023 of the 3054 patients included in this analysis (99.0\%). Of the 765 patients who were included in the assessment of response to ablation at 6 months to 1 year after the procedure, $621(81.2 \%)$ were considered to have had "treatment success". There were no significant differences in the proportions of patients who had hypothyroidism symptoms before the first and after the second dose of thyrotropin alfa.

Conclusion: In this large post-marketing surveillance study, thyrotropin alfa was well tolerated and showed effectiveness that was comparable to that observed in randomised, controlled trials.

Keywords: Ablation; Diagnosis; Japanese; Postmarketing surveillance; Recombinant human thyrotropin alfa; Real-world evidence; Thyroid cancer; Thyroid-stimulating hormone 


\section{Key Summary Points}

Why carry out this study?

There is a lack of real-world data on the clinical effectiveness and safety of thyrotropin alfa (recombinant human thyroid-stimulating hormone) in Japanese patients

This study was conducted to investigate the clinical effectiveness and safety of thyrotropin alfa, either as a diagnostic or therapeutic agent, in a real-world population of Japanese patients $(n>9000)$ between May 2012 and October 2018

\section{What was learned from this study?}

Thyrotropin alfa was generally well tolerated, with adverse drug reactions being reported in $9.4 \%$ and $5.8 \%$ of patients who received it for diagnostic and therapeutic (ablation) purposes, respectively

Over $80 \%$ of patients who received thyrotropin alfa for ablation were considered to have a successful treatment outcome 6-12 months post-procedure

In real-world use in Japan, thyrotropin alfa appears to have clinical effects comparable to those achieved in randomised controlled trials in the Japanese population

\section{INTRODUCTION}

Thyroid cancer is relatively rare, with approximately 3700 and 52,890 new cases occurring each year in the UK and the USA, respectively $[1,2]$. In Japan, the estimated number of thyroid cancer cases was 15,629 (4233 men and 11,396 women) in 2013 [3]. The crude mortality rate per 100,000 individuals was 0.96 for men and 1.86 for women [3].
Radioactive iodine (RAI) is used in both the diagnosis and treatment of thyroid cancer [4]. Adjunct RAI therapy is recommended for intermediate- and high-risk patients according to the American Thyroid Association (ATA) stratification system following surgery [4]. In patients with differentiated thyroid cancer, residual or metastatic thyroid tissue should be monitored every $0.5-1$ year, which requires a thyroglobulin (Tg) test. To perform this test accurately, patients should have no circulating thyroid hormone in order to elicit an increase in endogenous thyroid-stimulating hormone (TSH). ATA guidelines recommend that the TSH level should increase to at least $30 \mathrm{mIU} / \mathrm{L}$ before RAI therapy or diagnostic testing [4]. Two methods are available for thyroid ablation prior to Tg testing: withdrawing the patient's thyroxine therapy or administering an agent to block endogenous TSH release.

Thyrotropin alfa (Thyrogen $^{\circledR}$, Genzyme, USA) is a recombinant human TSH that is approved in the EU, the USA and Japan for use with serum $\mathrm{Tg}$ testing with or without RAI imaging for the detection of thyroid remnants and well-differentiated thyroid cancer in postthyroidectomy patients, as well as for use in combination with RAI for ablation of thyroid tissue remnants in patients who have undergone a near-total or total thyroidectomy for well-differentiated thyroid cancer and who do not have evidence of metastatic disease $[5,6]$. Thyrotropin alfa is administered as an intramuscular injection and has been used in more than 45 countries. ATA guidelines recommend using thyrotropin alfa as an alternative to thyroxine withdrawal for remnant ablation or adjuvant therapy in patients who have undergone near-total or total thyroidectomy [4].

While a number of large, multicentre clinical trials (such as HiLo [7] and ESTIMABL [8]) have demonstrated the effectiveness and safety of thyrotropin alfa for the management of thyroid cancer, real-world evidence is lacking. In addition, a total of only ten patients with differentiated thyroid cancer took part in a clinical trial of thyrotropin alfa conducted in Japan [9]. To address this knowledge gap, a post-marketing surveillance study of thyrotropin alfa in 
Japanese patients was conducted, the results of which are reported here.

\section{METHODS}

\section{Study Design and Patients}

This was a post-marketing surveillance study conducted to investigate the safety and effectiveness of thyrotropin alfa in Japan. There are two approved indications for thyrotropin alfa in Japan: (1) to support diagnosis, in combination with RAI scintigraphy and serum $\mathrm{Tg}$ test, or $\mathrm{Tg}$ test alone for patients who had a near-total or total thyroidectomy for differentiated thyroid cancer; and (2) as an adjunctive treatment for RAI ablation of thyroid tissue remnants in patients who have had a near-total or total thyroidectomy for well-differentiated thyroid cancer and who have no evidence of metastatic thyroid cancer.

The total study period was from January 2009 to December 2016 for indication 1 and from May 2012 to October 2018 for indication 2. All patients who received thyrotropin alfa for indication 1 or 2 during the respective timeframes were registered in this study using an internet-based central registration system.

The study was conducted in accordance with the relevant Japanese regulations [Ministerial Ordinance on Good Post-Marketing Study Practice (GPSP), Ministry of Health, Labour and Welfare Ordinance Number 171, December 20, 2004]. The study protocol was reviewed and approved by the Japanese regulatory authority prior to study initiation. The study underwent review by the ethics committees of the participating medical institutions. Informed consent was not acquired during this study, because GPSP does not require informed consent acquisition for post-marketing surveillance studies. However, only sites which agreed to the publication of the study findings were included.

\section{Data Collection}

Each physician submitted case report forms (CRFs) to the registration system approximately
1 month after the end of the 2-week observation period following $\mathrm{Tg}$ testing, scintigraphy or ablation. If thyrotropin alfa was administered as adjunctive treatment for ablation, follow-up was conducted using follow-up CRFs for the assessment of response ablation for up to 3 years.

The following information was collected: patient demographics [age, sex, pregnancy, breastfeeding, height, body weight, inpatient/ outpatient status, treatment experience with thyrotropin alfa (number of diagnostic tests), medical history, history of allergy, and presence of complications (including renal and hepatic impairment)]; characteristics of differentiated thyroid cancer [histological classification, time of occurrence, history of surgery (thyroidectomy), history of thyroid remnant ablation with RAI, and indication for the use of thyrotropin alfa]; details of thyrotropin alfa administration, including the number of doses; concomitant treatments; adverse drug reactions (ADRs); restriction of dietary iodine intake if scintigraphy was performed; anti-TSH antibody status (in potentially antibody-positive patients as determined by the treating physician); results of $\mathrm{Tg}$ testing and scintigraphy; and symptoms of hypothyroidism.

\section{Outcomes and Measures}

Patients who received at least one dose of thyrotropin alfa were included in the safety analysis set. Patients who were included in this set and did not meet any of the following criteria were included in the effectiveness analysis set: did not receive two doses of thyrotropin alfa every $24 \mathrm{~h}$, had a history of surgery for thyroid cancer other than total or near-total thyroidectomy, had thyroid cancer other than differentiated thyroid carcinoma, did not undergo $\mathrm{Tg}$ testing or scintigraphy (for patients who received thyrotropin alfa as a diagnostic), were not treated with radio-iodine (for patients who received thyrotropin alfa for ablation assistance), or received thyrotropin alfa for an offlabel indication.

The main outcome of the study was the proportion of patients in the safety analysis set 
who had ADRs. Adverse events (AEs) were defined as unintended, harmful events that were considered as such by the attending physician or the sponsor. ADRs are defined as adverse events other than "no relation to study drug", which were evaluated by the attending physician or the sponsor. ADRs were classified according to the International Council for Harmonisation of Technical Requirements for Pharmaceuticals for Human Use Medical Dictionary for Regulatory Activities, Japanese edition, v.21.0. Information on serious AEs, which were determined serious either by the physician or the sponsor, was also collected.

The effectiveness of thyrotropin alfa as a diagnostic was assessed in patients who were included in the effectiveness analysis set, had a $\mathrm{Tg}$ test, history of residual thyroid destruction due to RAI, and did not express anti-Tg antibodies. This study was designed based on the USA guidelines [10]. Tg testing results were classified into four categories: $\mathrm{Tg} \leq 2 \mathrm{ng} / \mathrm{mL}$, $\mathrm{Tg}>2$ to $<5 \mathrm{ng} / \mathrm{mL}, \mathrm{Tg} \geq 5$ to $<10 \mathrm{ng} / \mathrm{mL}$, and $\mathrm{Tg} \geq 10 \mathrm{ng} / \mathrm{mL}$, where $\leq 2 \mathrm{ng} / \mathrm{mL}$ was defined as "negative" and $>2 \mathrm{ng} / \mathrm{mL}$ was defined as "positive".

The results of scintigraphy were evaluated for resolution and quality of visualisation in patients who were included in the effectiveness analysis set and had a scintigram. Resolution was classified as "readable" or "not readable" by the reporting physician. Quality of visualisation

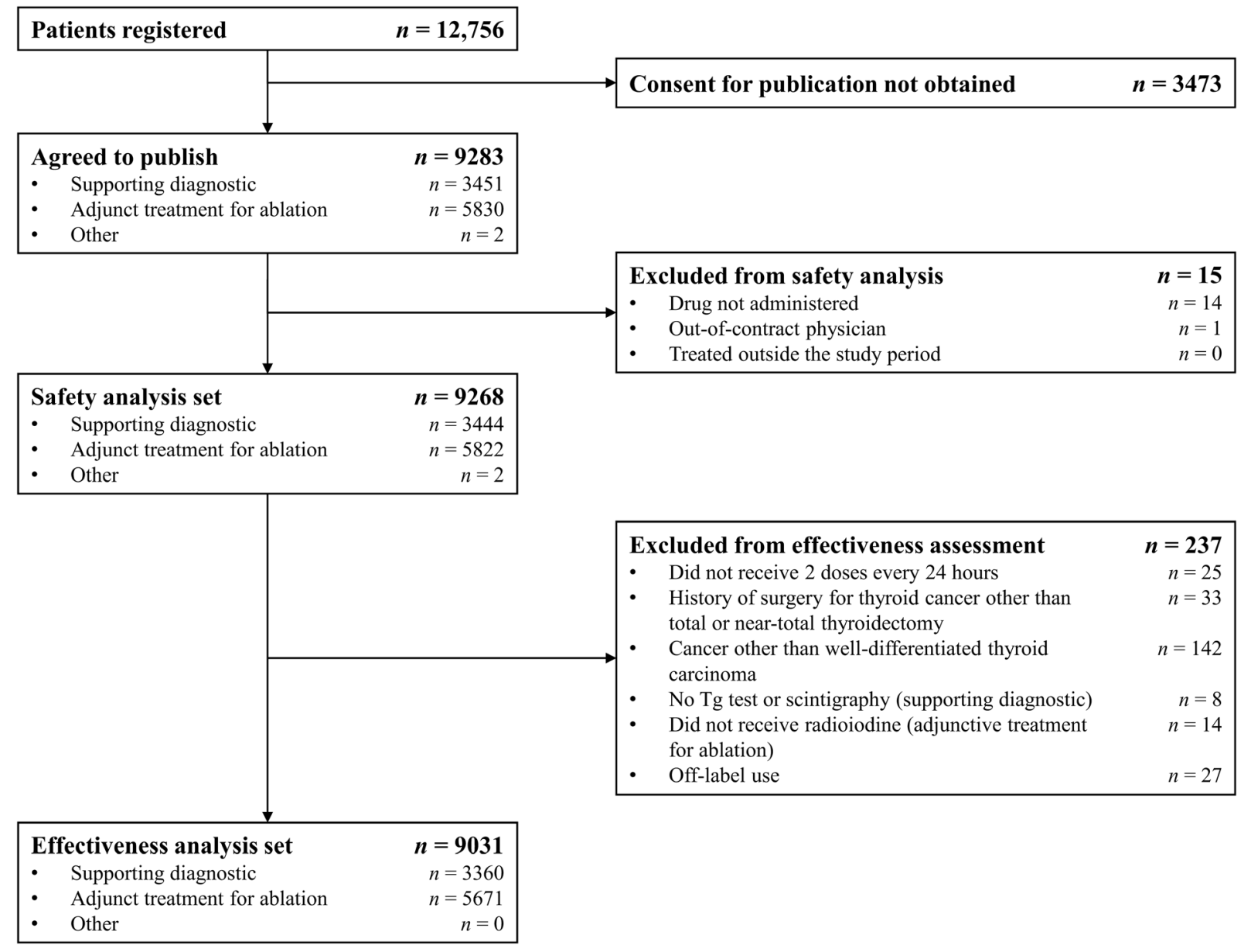

Fig. 1 Disposition of patients 
Table 1 Baseline characteristics of patients

\begin{tabular}{|c|c|c|c|c|}
\hline & $\begin{array}{l}\text { Total } \\
(n=9268)\end{array}$ & $\begin{array}{l}\text { Supporting } \\
\text { diagnostic }(n=3444)\end{array}$ & $\begin{array}{l}\text { Adjunctive treatment } \\
\text { for ablation }(n=5822)\end{array}$ & Other $(n=2)$ \\
\hline Female sex, $n(\%)$ & $6447(69.6)$ & $2472(71.8)$ & $3974(68.3)$ & $1(50.0)$ \\
\hline \multicolumn{5}{|l|}{ Age, years } \\
\hline Mean (SD) & $56.0(15.0)$ & $57.0(14.6)$ & $55.5(15.2)$ & $58.5(24.8)$ \\
\hline$<15$ & $12(0.1)$ & $3.0(0.1)$ & $9(0.2)$ & - \\
\hline$\geq 15-<65$ & $6021(65.0)$ & $2192(63.6)$ & $3828(65.8)$ & $1(50.0)$ \\
\hline$\geq 65$ & $3235(34.9)$ & $1249(36.3)$ & $1985(34.1)$ & $1(50.0)$ \\
\hline Unknown/unstated & - & - & - & - \\
\hline \multicolumn{5}{|l|}{ Body weight, kg } \\
\hline$n$ & 8792 & 3235 & 5556 & 1 \\
\hline Mean (SD) & $60.2(13.1)$ & $59.7(12.6)$ & $60.4(13.3)$ & $61.3(-)$ \\
\hline \multicolumn{5}{|c|}{ Body mass index, $\mathrm{kg} / \mathrm{m}^{2}$} \\
\hline$n$ & 8720 & 3197 & 5522 & 1 \\
\hline Mean (SD) & $23.4(4.1)$ & $23.4(4.0)$ & $23.5(4.2)$ & $27.6(-)$ \\
\hline \multicolumn{5}{|c|}{ Inpatient/outpatient at registration } \\
\hline Outpatient & $6535(70.5)$ & $2908(84.4)$ & $3626(62.3)$ & $1(50.0)$ \\
\hline Inpatient & $2713(29.3)$ & $532(15.4)$ & $2180(37.4)$ & $1(50.0)$ \\
\hline Unknown/unstated & $20(0.2)$ & $4(0.1)$ & $16(0.3)$ & - \\
\hline \multicolumn{5}{|l|}{ Comorbidities $^{\mathrm{a}}$} \\
\hline No & $4518(48.7)$ & $1882(54.6)$ & $2636(45.3)$ & - \\
\hline Yes & $4741(51.2)$ & $1562(45.4)$ & $3177(54.6)$ & $2(100.0)$ \\
\hline Unknown/unstated & $9(0.1)$ & - & $9(0.2)$ & - \\
\hline \multicolumn{5}{|c|}{ Dose of radioactive iodine $(\mathrm{mCi})$ as supporting diagnostic } \\
\hline$n$ & 2266 & 2266 & - & - \\
\hline Median (min, $\max )$ & $8.4(0.3,131.0)$ & $8.4(0.3,131.0)$ & - & - \\
\hline \multicolumn{5}{|c|}{ Dose of radioactive iodine $(\mathrm{mCi})$ as adjunctive treatment for ablation } \\
\hline$n$ & 5776 & - & 5776 & - \\
\hline Median (min, max) & $30(3,300)$ & - & $30(3,300)$ & - \\
\hline \multicolumn{5}{|c|}{ Dose of thyrotropin alfa } \\
\hline$n$ & 9268 & 3444 & 5822 & 2 \\
\hline Median $(\min , \max )$ & $2(1,2)$ & $2(1,2)$ & $2(1,2)$ & $2(2,2)$ \\
\hline
\end{tabular}

$S D$ standard deviation

a Comorbidities were all coexisting disorders, including kidney dysfunction, liver dysfunction, and others 
of the thyroid bed, neck other than thyroid bed (cervical lymph node metastasis), mediastinal metastasis, lung metastasis or other distant metastasis sites was assessed and classified as "visualised", "not visualised" or "indeterminate" by the reporting physician.

Sixteen symptoms of hypothyroidism were evaluated before the first and after the second dose of thyrotropin alfa by the treating physician who selected "no", "suspected" or "yes" for each symptom in the CRF. For the purposes of this analysis, any symptoms marked as "suspected" or "yes" were considered to be present, whereas only symptoms marked as "no" were considered to be absent.

In addition, response to ablation was evaluated at 6 months to 1 year after ablation. Ablation was evaluated based on response criteria of "no visualisation of thyroid bed" or "RAI uptake of $0.1 \%$ or less" using results rated by the reporting physician as either "success", "inadequate response", "without success" or "unevaluable".

\section{Statistical Analysis}

The incidence of ADRs was compared among subgroups by patient characteristics. Comparisons between subgroups were made using Fisher's exact test or chi-squared test with a significance level of 0.05 .

\section{RESULTS}

\section{Patient disposition and characteristics}

By the end of study period (October 15, 2018), 12,756 patients' data had been collected. Of these, 9283 patients from the 101 hospitals/clinics that agreed to the publication of data, including 3451 patients who received thyrotropin alfa for diagnostic purposes and 5830 patients who received it therapeutically. In addition, one patient received thyrotropin alfa for lymph node metastasis and one patient for Graves' disease. Of these, 9268 patients were included in the safety analysis set and 9031 were included in the effectiveness analysis set
(Fig. 1). The characteristics of patients at baseline are summarised in Tables 1 and 2 .

\section{Safety}

A total of 853 individual ADRs were recorded in 660 patients $(7.1 \%)$ in the safety analysis set. ADRs occurred in 9.4\% $(n=324)$ of patients who received thyrotropin alfa as a diagnostic and $5.8 \%(n=336)$ of patients who received it as treatment. The most common ADR was nausea $(4.0 \%$ of patients in the total safety population, $5.4 \%$ of patients in the diagnostic group and $3.2 \%$ of patients in the treatment group). The second and third most common ADRs were vomiting $(0.7 \%$ of patients in the total safety population, $0.8 \%$ of patients in the diagnostic group and $0.6 \%$ of patients in the treatment group) and headache $(0.6 \%, 0.7 \%$ and $0.6 \%$, respectively).

Thirty-eight serious AEs were reported in 25 patients (Table 3); 33 of these events had resolved or were in remission at the time of analysis, 3 were not resolved and the outcomes of 2 were unknown. Of the serious AEs, 16 events $(n=11)$ were considered to be related to thyrotropin alfa (SADRs). Fourteen SADR events were resolved or in remission, including one patient who received thyrotropin alfa as a diagnostic and was hospitalised for acute myocardial infarction. This patient was in remission at the time of analysis. One patient with nephrotic syndrome had been on treatment at the time of data cut-off and the outcome of a patient with back pain was not known.

\section{Effectiveness}

A total of 1835 patients were eligible for the analysis of the effectiveness of thyrotropin alfa to support diagnostic Tg testing. The Tg value was $\leq 2 \mathrm{ng} / \mathrm{mL}$ in 851 patients, $>2$ to $<5 \mathrm{ng} /$ $\mathrm{mL}$ in 222 patients, $\geq 5$ to $<10 \mathrm{ng} / \mathrm{mL}$ in 166 patients, and $\geq 10 \mathrm{ng} / \mathrm{mL}$ in 596 patients. After the second dose of thyrotropin alfa, the Tg test was positive in $53.6 \%$ of patients who used this drug as a diagnostic $(n=1835)$. Median (range) $\mathrm{Tg}$ was $0.50(0.00-5677.00) \mathrm{ng} / \mathrm{mL}$ before the 
Table 2 Patient characteristics related to thyroid cancer

\begin{tabular}{|c|c|c|c|c|}
\hline & $\begin{array}{l}\text { Total } \\
(n=9268)\end{array}$ & $\begin{array}{l}\text { Supporting } \\
\text { diagnostic }(n=3444)\end{array}$ & $\begin{array}{l}\text { Adjunctive treatment } \\
\text { for ablation }(n=5822)\end{array}$ & Other $(n=2)$ \\
\hline \multicolumn{5}{|c|}{ Histologic classification of differentiated thyroid cancer } \\
\hline Papillary carcinoma & $8504(91.8)$ & $3145(91.3)$ & $5357(92.0)$ & $2(100.0)$ \\
\hline Follicular carcinoma & $694(7.5)$ & $277(8.0)$ & $417(7.2)$ & $0(0)$ \\
\hline Other & $164(1.8)$ & $65(1.9)$ & $99(1.7)$ & $0(0)$ \\
\hline Unknown/unstated & $4(0.0)$ & $0(0)$ & $4(0.1)$ & $0(0)$ \\
\hline \multicolumn{5}{|l|}{ Duration of illness, years } \\
\hline$<5$ & $3071(33.1)$ & $991(28.8)$ & $2080(35.7)$ & $0(0)$ \\
\hline$\geq 5-<10$ & $418(4.5)$ & $210(6.1)$ & $207(3.6)$ & $1(50.0)$ \\
\hline$\geq 10$ & $410(4.4)$ & $237(6.9)$ & $173(3.0)$ & $0(0)$ \\
\hline Unknown & $5369(57.9)$ & $2006(58.2)$ & $3362(57.7)$ & $1(50.0)$ \\
\hline \multicolumn{5}{|l|}{ Number of previous surgeries } \\
\hline 1 & $7838(84.6)$ & $2878(83.6)$ & $4960(85.2)$ & $0(0)$ \\
\hline 2 & $1327(14.3)$ & $513(14.9)$ & $814(14.0)$ & $0(0)$ \\
\hline 3 & $71(0.8)$ & $38(1.1)$ & $33(0.6)$ & $0(0)$ \\
\hline$\geq 4$ & $26(0.3)$ & $14(0.4)$ & $11(0.2)$ & $1(50.0)$ \\
\hline Unknown/unstated & $6(0.1)$ & $1(0.0)$ & $4(0.1)$ & $1(50.0)$ \\
\hline \multicolumn{5}{|l|}{ Previous thyroid surgery } \\
\hline Total thyroidectomy & $9020(97.3)$ & $3267(94.9)$ & $5752(98.8)$ & $1(50.0)$ \\
\hline Near-total thyroidectomy & $184(2.0)$ & $131(3.8)$ & $53(0.9)$ & $0(0)$ \\
\hline Subtotal thyroidectomy & $17(0.2)$ & $13(0.4)$ & $4(0.1)$ & $0(0)$ \\
\hline Partial thyroidectomy & $2(0.0)$ & $2(0.1)$ & $0(0)$ & $0(0)$ \\
\hline Hemithyroidectomy & $36(0.4)$ & $28(0.8)$ & $8(0.1)$ & $0(0)$ \\
\hline Unknown/unstated & $9(0.1)$ & $3(0.1)$ & $5(0.1)$ & $1(50.0)$ \\
\hline \multicolumn{5}{|l|}{ Previous ablations, times } \\
\hline None & $5454(58.8)$ & $684(19.9)$ & $4769(81.9)$ & $1(50.0)$ \\
\hline Any & $3783(40.8)$ & $2741(79.6)$ & $1041(17.9)$ & $1(50.0)$ \\
\hline 1 & $3231(34.9)$ & $2402(69.7)$ & $828(14.2)$ & $1(50.0)$ \\
\hline 2 & $369(4.0)$ & $212(6.2)$ & $157(2.7)$ & $0(0)$ \\
\hline 3 & $94(1.0)$ & $63(1.8)$ & $31(0.5)$ & $0(0)$ \\
\hline$\geq 4$ & $89(1.0)$ & $64(1.9)$ & $25(0.4)$ & $0(0)$ \\
\hline Unknown/unstated & $31(0.3)$ & $19(0.6)$ & $12(0.2)$ & $0(0)$ \\
\hline
\end{tabular}


Table 2 continued

$\begin{array}{llll}\begin{array}{l}\text { Total } \\ (n=9268)\end{array} & \begin{array}{l}\text { Supporting } \\ \text { diagnostic }(n=3444)\end{array} & \begin{array}{l}\text { Adjunctive treatment } \\ \text { for ablation }(n=5822)\end{array} & \text { Other }(n=2) \\ \end{array}$

Total radioiodine dose, $\mathrm{mCi}$

$\begin{array}{lll}<10 & 37(0.4) & 36(1.0) \\ \geq 10-<30 & 112(1.2) & 101(2.9) \\ \geq 30-<50 & 2046(22.1) & 1462(42.5) \\ \geq 50-<100 & 680(7.3) & 532(15.4) \\ \geq 100 & 908(9.8) & 610(17.7)\end{array}$

Time from onset to date of total thyroidectomy, years

$\begin{array}{lllll}<5 & 3287(35.5) & 1132(32.9) & 2154(37.0) & 1(50.0) \\ \geq 5-<10 & 205(2.2) & 76(2.2) & 129(2.2) & 0(0) \\ \geq 10 & 176(1.9) & 79(2.3) & 97(1.7) & 0(0) \\ \text { Unknown } & 5352(57.7) & 1980(57.5) & 3372(57.9) & 0(0)\end{array}$

Data are $n(\%)$

first dose and $2.30(0.04-29,496.00) \mathrm{ng} / \mathrm{mL}$ after the second dose.

The scintigram was rated as "readable" in 3023 of the 3054 patients included in this analysis (99.0\%). The detection rate was $20.0 \%$ for the thyroid gland bed and $25.4 \%$ for any part of the body. Twenty patients who received thyrotropin alfa as a diagnostic had an additional $\mathrm{Tg}$ test using thyroid hormone withdrawal.

Of the 765 patients who were included in the assessment of response to RAI treatment at 6 months to 1 year after the procedure, 621 $(81.2 \%)$ were considered to have had "treatment success". Scintigraphy of the thyroid bed was performed in 764 of the 765 patients and visualisation was achieved 62 patients, while no visualisation was achieved in 606 (79.3\%) patients. Of the patients who received thyrotropin alfa as treatment, 26 patients had additional scintigraphy or Tg testing with thyroid hormone withdrawal.

The proportion of patients who had any of the 16 hypothyroid symptoms after the second dose of thyrotropin alfa was not significantly different to the proportion before the first dose of thyrotropin alfa (Table 4), and this was the case in patients receiving thyrotropin alfa for diagnostic or therapeutic indications.

\section{DISCUSSION}

To our knowledge, this is the largest study to date evaluating the safety and effectiveness of thyrotropin alfa in patients with thyroid cancer in Japan. These results are consistent with prior studies showing that thyrotropin alfa has an acceptable safety profile and is generally well tolerated $[7,8,11]$.

After 1 year of treatment, the response rate was $81 \%$. This finding is comparable with those of a study which compared low-dose RAI plus thyrotropin alfa with high-dose RAI plus thyroid hormone withdrawal, in which the 6- to 9 -month response rates were $84.3 \%$ and $87.6 \%$, respectively [7]. The rates of recurrence at 3 years were $1.5 \%$ in patients who received thyrotropin alfa and $2.1 \%$ in those who underwent thyroid hormone withdrawal [12]. The high response rate of thyrotropin alfa in our study is encouraging, since the data were collected under real-world conditions and, therefore, are more generalisable to a typical clinical 
Table 3 Number of patients who had a serious adverse event during the study

\begin{tabular}{llll}
\hline Preferred term & $\begin{array}{l}\text { Total } \\
(\boldsymbol{n}=\mathbf{9 2 6 8})\end{array}$ & $\begin{array}{l}\text { Supporting } \\
\text { diagnostic }(\boldsymbol{n}=\mathbf{3 4 4 4})\end{array}$ & $\begin{array}{l}\text { Adjunctive treatment } \\
\text { for ablation }(\boldsymbol{n}=\mathbf{5 8 2 2})\end{array}$ \\
\hline Vomiting & 4 & - & 4 \\
Nausea & 2 & - & 2 \\
Loss of consciousness & 1 & 1 & - \\
Back pain & 1 & 1 & - \\
Atrial fibrillation & 1 & - & 1 \\
Pleural effusion & 1 & - & 1 \\
Acute myocardial infarction & 1 & 1 & - \\
Dizziness & 1 & - & 1 \\
Laryngeal oedema & 1 & - & 1 \\
Cancer pain & 1 & 1 & - \\
Nephrotic syndrome & 1 & - & 1 \\
Hyponatraemia & 1 & - & 1 \\
\hline
\end{tabular}

practice population than data from randomised controlled trials in highly selected patient populations [13].

Using thyrotropin alfa for thyroid ablation before RAI administration is becoming the standard of care in many countries in preference to thyroid hormone withdrawal $[14,15]$. This is based on data showing diagnostic and therapeutic equivalence between the two thyroid ablation techniques, but thyrotropin alfa is associated with fewer adverse events and no deterioration in quality of life caused by hypothyroid symptoms [16]. In the present study, the incidence of hypothyroid symptoms before thyrotropin alfa administration was low, and there were no significant differences in the proportion of patients who had any of the 16 symptoms before the first and after the second dose of thyrotropin alfa, whether in patients who received it as a supporting diagnostic or as adjunctive treatment for ablation, supporting the lack of impact of thyrotropin alfa on these signs/symptoms. The ability to continue levothyroxine treatment during thyroid ablation is an important advantage of thyrotropin alfa [14]. Patients who undergo thyroid hormone withdrawal experience significantly more symptoms of hypothyroidism, including dysphoric mood, compared with patients who receive thyrotropin alfa as the RAI stimulant [11], and this is associated with a significant (albeit transient) deterioration in quality of life [16].

As thyrotropin alfa can be used as an alternative for thyroid hormone withdrawal, it is important to evaluate whether an additional scintigram or Tg testing with thyroid hormone withdrawal was needed after using thyrotropin alfa for either diagnosis or treatment. In our study, very few patients $(1.5 \%$ in the treatment group and $1.1 \%$ in the diagnosis group) had additional testing with hormone withdrawal. However, our study was not designed to collect detailed information on the reason for additional testing, so no clear conclusions can be drawn from the rates of additional testing.

This study included a large population of more than 9000 patients with thyroid cancer. The mean age of the patients was 56 years; however, $65 \%$ were less than 65 years old. The 
Table 4 Incidence of the signs or symptoms of hypothyroidism before the first and after the second dose of thyrotropin alfa

\begin{tabular}{llcc}
\hline Sign/symptom & $\begin{array}{l}\text { Number of } \\
\text { patients evaluated }\end{array}$ & \multicolumn{2}{l}{ Number of patients affected, $\boldsymbol{n}(\%)$} \\
\cline { 3 - 4 } & 6902 & $17(0.25)$ & After second dose \\
\hline Reduced sweating & 6904 & $81(1.17)$ & $18(0.26)$ \\
Dry skin & 6905 & $93(1.35)$ & $72(1.04)$ \\
Coldness & 6904 & $60(0.87)$ & $87(1.26)$ \\
Weight gain & 6908 & $109(1.58)$ & $49(0.71)$ \\
Constipation & 6898 & $254(3.68)$ & $104(1.51)$ \\
Hoarseness & 6906 & $33(0.48)$ & $236(3.42)$ \\
Dysesthesia & 6907 & $47(0.68)$ & $47(0.68)$ \\
Hearing loss & 6905 & $20(0.29)$ & $43(0.62)$ \\
Slow movement & 6906 & $39(0.56)$ & $25(0.36)$ \\
Rough skin & 6906 & $32(0.46)$ & $40(0.58)$ \\
Skin coldness & 6905 & $19(0.28)$ & $34(0.49)$ \\
Oedema of the eyelids & 6877 & $32(0.47)$ & $20(0.29)$ \\
Slow Achilles tendon reflex & 6905 & $3(0.04)$ & $15(0.22)$ \\
Decreased pulse rate & 6903 & $64(0.93)$ & $6(0.09)$ \\
Oedema & 6875 & $158(2.30)$ & $48(0.70)$ \\
Leg cramps & & & $119(1.73)$ \\
\hline
\end{tabular}

majority of patients $(91.8 \%)$ had papillary carcinoma and $84.6 \%$ had undergone one surgery, which in most cases (97.3\%) was total thyroidectomy. The duration of illness was less than 5 years in $33.1 \%$ of included patients; however, it was unknown in $57.9 \%$, as the date of first diagnosis was not recorded in this study. These data suggest that thyrotropin alfa is being used for patients with low- and intermediaterisk differentiated thyroid cancer, in accordance with guidelines [4].

This study had a number of limitations. Firstly, only Japanese patients were included and, therefore, the results may not be generalisable to other populations. Secondly, the overall duration of the study was long and guideline recommendations and treatment and diagnostic options changed during this period, which could have resulted in inconsistency in clinical practice.

\section{CONCLUSIONS}

This was the largest study to date to evaluate the safety and effectiveness of thyrotropin alfa in Japanese patients with thyroid cancer. The results show that thyrotropin alfa was generally well tolerated and had an acceptable safety profile. The real-world effectiveness of thyrotropin alfa in the present study was comparable to that observed in previous randomised controlled trials. The use of thyrotropin alfa was not associated with a deterioration in the symptoms of hypothyroidism. 


\section{ACKNOWLEDGEMENTS}

Funding. This study was funded by Sanofi K.K., who also funded the journal's Rapid Service and Open Access Fees.

Medical Writing and Editorial Assistance. The authors would like to thank Yoshiko Okamoto of inScience Communications, who wrote the outline, and Georgii Filatov of inScience Communications, who wrote the first draft of this manuscript. This medical writing assistance was funded by Sanofi K.K.

Authorship. All named authors meet the International Committee of Medical Journal Editors (ICMJE) criteria for authorship for this article, take responsibility for the integrity of the work as a whole, and have given their approval for this version to be published.

Authorship Contributions. Shiho Yamane, contributed to study conception and design, and Takeshi Seto contributed to enrolment of patients and operations. All authors interpreted the results, and reviewed and approved the manuscript for submission.

Disclosures. Rie Kanamori, Shiho Yamane and Takeshi Seto are employees of Sanofi K.K., Japan.

Compliance with Ethics Guidelines. The study was conducted in accordance with the relevant Japanese regulations (Ministerial Ordinance on Good Post-Marketing Study Practice, Ministry of Health, Labour and Welfare Ordinance Number 171, December 20, 2004). The study protocol was reviewed and approved by the Japanese regulatory authority prior to study initiation. The study underwent review by the ethics committees of the participating medical institutions.

Data Availability. Qualified researchers may request access to patient-level data and related documents (including, e.g., the clinical study report, study protocol with any amendments, blank case report form, statistical analysis plan, and dataset specifications). Patient-level data will be anonymised, and study documents will be redacted to protect the privacy of trial participants. Further details on Sanofi's data sharing criteria, eligible studies, and process for requesting access can be found at https://www.clinicalstudydatarequest.com.

Open Access. This article is licensed under a Creative Commons Attribution-NonCommercial 4.0 International License, which permits any non-commercial use, sharing, adaptation, distribution and reproduction in any medium or format, as long as you give appropriate credit to the original author(s) and the source, provide a link to the Creative Commons licence, and indicate if changes were made. The images or other third party material in this article are included in the article's Creative Commons licence, unless indicated otherwise in a credit line to the material. If material is not included in the article's Creative Commons licence and your intended use is not permitted by statutory regulation or exceeds the permitted use, you will need to obtain permission directly from the copyright holder. To view a copy of this licence, visit http://creativecommons.org/licenses/by$\mathrm{nc} / 4.0 /$.

\section{REFERENCES}

1. Cancer Research UK. What is thyroid cancer? 2018. https://about-cancer.cancerresearchuk.org/aboutcancer/thyroid-cancer/about-thyroid-cancer. Accessed 22 Jan 2021.

2. Surveillance, Epidemiology, and End Results Program (SEER). Cancer Stat Facts: Thyroid Cancer. https://seer.cancer.gov/statfacts/html/thyro.html. Accessed 22 Jan 2021.

3. Committee for Preparation of Clinical Guidelines for Thyroid Tumors. Guidelines for the Management of Thyroid Tumors 2018. Official Journal of the Japan Association of Endocrine Surgeons and the Japanese Society of Thyroid Surgery. 2018;35(Suppl 3):1-87.

4. Haugen BR, Alexander EK, Bible KC, et al. 2015 American Thyroid Association Management Guidelines for Adult Patients with Thyroid Nodules and Differentiated Thyroid Cancer: The American 
Thyroid Association Guidelines Task Force on Thyroid Nodules and Differentiated Thyroid Cancer. Thyroid. 2016;26(1):1-133. https://doi.org/10. 1089/thy.2015.0020.

5. European Medicines Agency (EMA). Thyrogen: EPAR-Product information. 2009. https://www. ema.europa.eu/en/documents/productinformation/thyrogen-epar-product-information en.pdf. Accessed 22 Jan 2021.

6. Genzyme Corporation. Thyrogen-thyrotropin alfa. https://www.accessdata.fda.gov/drugsatfda docs/label/2008/020898s038lbl.pdf. Accessed 22 Jan 2021.

7. Mallick U, Harmer C, Yap B, et al. Ablation with low-dose radioiodine and thyrotropin alfa in thyroid cancer. N Engl J Med. 2012;366(18):1674-85. https://doi.org/10.1056/NEJMoa1109589.

8. Schlumberger M, Catargi B, Borget I, et al. Strategies of radioiodine ablation in patients with low-risk thyroid cancer. N Engl J Med. 2012;366(18): 1663-73. https://doi.org/10.1056/NEJMoa1108586.

9. Konishi J, Tamaki N, Nakada K, et al. Assessment of the efficacy, safety and pharmacokinetics of SKG-02 (recombinant human TSH) in postoperative diagnosis of well-differentiated thyroid cancer-a Japanese prospective, controlled, multicenter openlabel study. Kaku igaku Jpn J Nucl Med. 2010;47(4): 479-96.

10. Cooper DS, Doherty GM, Haugen BR, et al. Revised American Thyroid Association management guidelines for patients with thyroid nodules and differentiated thyroid cancer. Thyroid. 2009;19(11): 1167-214. https://doi.org/10.1089/thy.2009.0110.
11. Ladenson PW, Braverman LE, Mazzaferri EL, et al. Comparison of administration of recombinant human thyrotropin with withdrawal of thyroid hormone for radioactive iodine scanning in patients with thyroid carcinoma. N Engl J Med. 1997;337(13):888-96. https://doi.org/10.1056/ NEJM199709253371304.

12. Dehbi HM, Mallick U, Wadsley J, Newbold K, Harmer C, Hackshaw A. Recurrence after low-dose radioiodine ablation and recombinant human thyroid-stimulating hormone for differentiated thyroid cancer (HiLo): long-term results of an open-label, non-inferiority randomised controlled trial. Lancet Diabetes Endocrinol. 2019;7(1):44-51. https://doi. org/10.1016/s2213-8587(18)30306-1.

13. Price D, Bateman ED, Chisholm A, et al. Complementing the randomized controlled trial evidence base. Evolution not revolution. Ann Am Thorac Soc. 2014;11(Suppl 2):S92-8. https://doi.org/10. 1513/AnnalsATS.201308-276RM.

14. Giovanella L, Duntas LH. MANAGEMENT OF ENDOCRINE DISEASE: The role of rhTSH in the management of differentiated thyroid cancer: pros and cons. Eur J Endocrinol. 2019;181(4):R133-45. https://doi.org/10.1530/EJE-19-0149.

15. Pacini F. Radioactive iodine activities for postsurgical thyroid ablation: the lower the better. Eur Thyroid J. 2012;1:213-5. https://doi.org/10.1159/ 000346154.

16. Borget I, Bonastre J, Catargi B, et al. Quality of life and cost-effectiveness assessment of radioiodine ablation strategies in patients with thyroid cancer: results from the randomized phase III ESTIMABL Trial. J Clin Oncol. 2015;33(26):2885-92. https:// doi.org/10.1200/JCO.2015.61.6722. 